\title{
A História da Matemática em livros didáticos dos anos iniciais do Ensino Fundamental
}

\section{The History of Mathematics in textbooks from the early years of Elementary School}

Franklin Fernando Ferreira Pachêco

Universidade Federal de Pernambuco (UFPE), Recife, PE, Brasil

https://orcid.org/0000-0002-4600-2103, pacheco.franklin9@gmail.com

Josinaldo José da Silva

Universidade Federal da Paraíba (UFPB), João Pessoa, PB, Brasil

b https://orcid.org/0000-0002-4814-1537, josinaldoj25@gmail.com

\begin{tabular}{l}
\hline Informações do Artigo \\
\hline Como citar este artigo \\
PACHÊCO, Franklin Fernando Ferreira; \\
SILVA, Josinaldo José da. A História da \\
Matemática em livros didáticos dos anos \\
iniciais do Ensino Fundamental. REMAT: \\
Revista Eletrônica da Matemática, Bento \\
Gonçalves, RS, v. 7, n. 1, p. e2006, 28 mar. \\
2021. DOI: \\
https://doi.org/10.35819/remat2021v7i1id4623
\end{tabular}

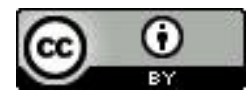

Histórico do Artigo

Submissão: 24 de setembro de 2020.

Aceite: 15 de dezembro de 2020.

Palavras-chave

História da Matemática

Livros Didáticos

Matemática

\section{Keywords}

History of Mathematics

Textbooks

Mathematics

\section{Resumo}

A presente pesquisa integra o conjunto de estudos voltados para o âmbito da Educação Matemática. Seu objetivo foi analisar a abordagem da História da Matemática em livros didáticos dos anos iniciais do Ensino Fundamental. Adotou-se três coleções de livros didáticos de Matemática (Vem Voar, Ligamundo e Ápis) do $1^{\circ}$ ao $5^{\circ}$ ano, aprovadas pelo Programa Nacional do Livro e do Material Didático 2019. Para analisar e discutir os resultados, adotou-se os três polos (Pré-análise, Exploração do Material e Tratamento dos resultados obtidos e interpretação) da análise do conteúdo proposta por Bardin (1977). Os resultados sinalizam para um pouco tratamento dado à História da Matemática na referida etapa do ensino. Dentre os conteúdos propostos para o processo de ensino e de aprendizagem da matemática do $1^{\circ}$ ao $5^{\circ}$ ano do Ensino Fundamental, verificou-se que, nos livros didáticos analisados, a ênfase da História da Matemática está centrada na discussão sobre os sistemas de numeração (maia, romano e egípcio). 


\section{Introdução}

Diversos episódios da História da Matemática apresentam que a interação do homem com seu meio permitiu a criação de conhecimentos matemáticos para sobreviver. Desde a antiguidade aos dias atuais, o homem, a partir da sociedade em que está situado, vem aperfeiçoando os conhecimentos da Matemática. Assim sendo, essa área do saber mostra que "[...] é importante olhar para o passado para estudar matemática, pois perceber as evoluções das ideias matemáticas observando somente o estado atual dessa ciência não nos dá toda a dimensão das mudanças" (SANTOS, 2009, p. 19).

Desse modo, compreender como se dá a construção do conhecimento matemático nas distintas culturas e épocas, potencializa o papel do homem no desenvolvimento da Matemática. Ao fazer esse resgate na Educação Básica, "a História da Matemática vem se consolidando como um importante recurso metodológico no processo de ensino e aprendizagem desse conhecimento" (PACHÊCO; SILVA; PACHÊCO, 2018, p. 109).

Sendo a História da Matemática, portanto, considerada um aporte para o professor explorar conhecimentos da matemática na sala de aula, os Parâmetros Curriculares Nacionais PCN (BRASIL, 1997, p. 34) apresentam que essa abordagem "pode esclarecer ideias matemáticas que estão sendo construídas pelo estudante, especialmente para dar respostas a alguns 'porquês' e, desse modo, contribuir para a constituição de um olhar mais crítico sobre os objetos de conhecimento". Ao considerar a História da Matemática enquanto recurso para o processo de ensino, o professor pode "entender alguns aspectos do processo de aprendizagem de seus estudantes e também as dificuldades e possíveis erros cometidos por eles durante esse processo" (BALESTRI; CYRINO; SAVIOLI, 2008, p. 14). Nessa perspectiva, ainda, o professor pode levar seus estudantes a entenderem:

(1) a matemática como uma criação humana; (2) as razões pelas quais as pessoas fazem matemática; (3) as necessidades práticas, sociais, econômicas e físicas que servem de estímulo ao desenvolvimento das ideias matemáticas; (4) as conexões existentes entre matemática e filosofia, matemática e religião, matemática e lógica, etc.; (5) a curiosidade estritamente intelectual que pode levar à generalização e extensão de ideias e teorias; (6) as percepções que os matemáticos têm do próprio objeto da matemática, as quais mudam e se desenvolvem ao longo do tempo; (7) a natureza de uma estrutura, de uma axiomatização e de uma prova (MIGUEL; MIORIM, 2011, p. 53).

Outro aspecto relevante, ao se discutir essa temática, é que se torna possível perceber que a Matemática não é uma ciência pronta e acabada, que não é passível de modificações; ela vem sendo aperfeiçoada desde os tempos remotos e, a cada dia, seus conhecimentos vão se modificando, contribuindo para o âmbito científico, econômico e tecnológico. Por isso, concorda-se com a afirmação de que a ideia do surgimento dos conhecimentos da Matemática deve "fazer parte da formação dos professores para que tenham elementos que lhes permitam mostrar aos estudantes a Matemática como ciência que não trata de verdades eternas, infalíveis e imutáveis, 
mas como ciência dinâmica, sempre aberta à incorporação de novos conhecimentos." (BRASIL, 1997, p. 30).

Sobre essa temática, diversos pesquisadores (CURY; MOTTA, 2008; MIGUEL; MIORIM, 2011; LOPES; ALVES, 2013; LOPES; FERREIRA, 2013; PEREIRA, 2016; PACHÊCO; SILVA; PACHÊCO, 2018) apontam que, no ambiente da sala de aula, o professor deve explorá-la com o intuito de propiciar aos estudantes a relevância da Matemática na vida do ser humano, em distintas épocas, elencando a trajetória dos diferentes conhecimentos e destacando os possíveis responsáveis pela criação, sistematização e método de resolução de conteúdos. Essa realidade, mesmo que de forma breve, apresenta-se em livros didáticos que se destinam ao processo de ensino e de aprendizagem da Matemática da Educação Básica. Nos livros didáticos, a História da Matemática é exposta de forma a situar o seu usuário (professor e/ou estudante) a compreender o surgimento daquele conceito e/ou conteúdo, entender que ele sofreu adaptações ao longo dos anos, situar o porquê de estudá-lo e qual sua funcionalidade na sociedade atual.

Dentre esse conjunto de pesquisas, Pachêco, Silva e Pachêco (2018) e Lopes e Alves (2013), que investigaram a História da Matemática em livros didáticos nos anos finais do Ensino Fundamental e Ensino Médio, respectivamente, apontam que essa temática é explorada de maneira superficial naquele material de apoio pedagógico. Esta pesquisa, portanto, teve o propósito de analisar a abordagem da História da Matemática em três coleções de livros didáticos dos anos iniciais do Ensino Fundamental. Esses materiais foram aprovados pelo Programa Nacional do Livro e do Material Didático (PNLD) de 2019. Escolheu-se, pois, livros didáticos como fonte avaliativa por ser um recurso muito usado pelo professor para o processo de ensino no ambiente escolar (CARVALHO; LIMA, 2010; BITTAR, 2017; PACHÊCO; SILVA, 2019). Concordase, ainda, que analisar livros didáticos é verificar como os conteúdos estão sendo propostos nesse material pelos autores para o processo de ensino e de aprendizagem, por isso "o uso de documentos em pesquisa deve ser apreciado e valorizado." (SÁ-SILVA; ALMEIDA; GUIDANI, 2009, p. 2).

Para a análise do conteúdo, utilizou-se a perspectiva de Bardin (1977), de modo a constituir três polos: I - Pré-Análise; II - Exploração do Material; III - Tratamento dos resultados obtidos e interpretação. Dessa forma, o próximo tópico deste trabalho expõe a revisão da literatura, em seguida são apresentados os procedimentos metodológicos, as análises e discussões dos resultados, as considerações finais e as referências.

\section{Revisão da literatura}

\subsection{A História da Matemática: o que a literatura apresenta sobre essa temática?}

No âmbito da Educação Matemática, a temática da História da Matemática tem sido alvo de diversas discussões e produções de pesquisas por distintos autores (CURY; MOTTA, 2008; MIGUEL; MIORIM, 2011; LOPES; ALVES, 2013; LOPES; FERREIRA, 2013; PACHÊCO; SILVA; 
PACHÊCO, 2018). Esses estudos apontam que a História da Matemática pode ser explorada enquanto recurso no processo de ensino e de aprendizagem de conteúdos matemáticos, ideia contemplada nos PCN (BRASIL, 1997; 1998) e na Base Nacional Comum Curricular - BNCC (BRASIL, 2018).

No contexto da Educação Básica, a abordagem da História da Matemática está explorada com ênfase em livros didáticos de Matemática. Para Pereira (2016), a presença dos aspectos históricos nesse tipo de material está justificada por duas perspectivas: a primeira, quando o autor deseja situar os usuários a entenderem como ocorreu o surgimento daquele conceito, e a segunda, por ser uma exigência do PNLD. Nessa perspectiva, "a História da Matemática também tem se transformado em assunto específico, um item a mais a ser incorporado ao rol de conteúdos, que muitas vezes não passa da apresentação de fatos ou biografias de matemáticos famosos" (BRASIL, 1997, p. 23).

Essa realidade exposta nos PCN (BRASIL, 1997) é encontrada nos estudos de Lopes e Alves (2013) e Pachêco, Silva e Pachêco (2018). Apesar da História da Matemática ser um elemento em que o professor pode se apoiar para o processo de ensino e promover a aprendizagem de estudantes, os resultados da pesquisa de Lopes e Alves (2013) sinalizam que essa temática, quando proposta, é apresentada de maneira superficial, sem um aprofundamento com o conteúdo, ou seja, "em nenhum capítulo são utilizados como fundamento do conteúdo ou como motivo de se estudar tal saber" (p. 12). Outro resultado destacado por Lopes e Alves (2013, p. 12) é que a "distribuição das notas históricas no livro didático encontram-se sempre destacadas, como leitura complementar, faltando articulação com o conteúdo em pauta".

Ao analisar uma coleção de livros didáticos dos anos finais do Ensino Fundamental, aprovada pelo PNLD 2017, os resultados do estudo de Pachêco, Silva e Pachêco (2018, p. 120) mostram "que apesar dos aspectos históricos serem relevantes para a abordagem dos diversos conteúdos da disciplina de matemática, esses se apresentam de maneira resumida". Os autores reafirmam os dados apontados por Lopes e Alves (2013), apresentando que os momentos históricos presentes na coleção explorada encontram-se "apenas como leituras complementares, sendo essas delineadas para definir e situar o leitor como se deu o surgimento do conteúdo em questão, mas que não há um aprofundamento no mesmo ou uma interligação a mais sobre o assunto a ser trabalhado." (PACHÊCO; SILVA; PACHÊCO, 2018, p. 121).

Pesquisas realizadas sobre essa temática nos anos iniciais do Ensino Fundamental (OLIVEIRA, 2016; SOUZA; FORTALEZA, 2016) apontam que é importante que o professor conceba uma formação que contemple conhecimentos sobre aspectos históricos da Matemática. Outro fator apontado como relevante por Oliveira (2016) e Souza e Santos Fortaleza (2016) diz respeito a abordar essa temática na sala de aula como indispensável para a construção dos conhecimentos dos estudantes para mostrar a eles, desde os primeiros anos escolares, que a 
Matemática é fruto da construção do homem, podendo estar, portanto, presente nas diversas situações do cotidiano.

\subsection{Os livros didáticos como recursos para o processo de ensino e de aprendizagem}

$\mathrm{Na}$ Educação Básica, independentemente da rede de ensino da instituição (privada ou pública), os livros didáticos são recursos que auxiliam o professor no processo de ensino (no planejamento e execução de suas aulas) e promovem a aprendizagem de estudantes. Sendo, portanto, um suporte para o professor e, por isso, quando se discute sobre recursos na educação, não é possível relegar os livros didáticos.

No contexto do processo de ensino e de aprendizagem, os livros didáticos, de acordo com Carvalho e Lima (2010), contemplam quatro polos: autor/livro didático; professor; estudante e Matemática. Esses polos podem ser compreendidos da seguinte maneira: o(s) autor(es) dos livros didáticos são os responsáveis por produzirem e sistematizarem os conteúdos no material para serem vivenciados no processo de ensino e de aprendizagem; o professor, de porte do livro didático, pode utilizá-lo para planejar suas aulas, ficando ao seu critério adotar ou não todas as recomendações (atividades) do livro; os estudantes, de posse do livro didático, podem estudar antes da aula proposta pelo professor ou posteriormente a ela; e a Matemática presente nos livros didáticos é fruto de estudos dos autores. Com isso, é possível ressaltar que o uso do livro didático no âmbito escolar possibilita que o autor converse com os outros dois sujeitos (estudante e professor) envolvidos no processo de ensino e aprendizagem. Assim, “[...] nesse diálogo, o livro é portador de escolhas sobre: o saber a ser estudado - no nosso caso, a Matemática -; os métodos adotados para que os estudantes consigam aprendê-lo mais eficazmente; a organização curricular ao longo dos anos de escolaridade" (CARVALHO; LIMA, 2010, p. 15).

Sobre a relevância dos livros didáticos para o processo de ensino e de aprendizagem, algumas pesquisas (BITTAR, 2017; PACHÊCO; SILVA, 2019) apontam que esse é o recurso mais usual no ambiente da sala de aula. Além disso, potencializa a funcionalidade desse material para o professor (produzir suas aulas) e do estudante estudar antes ou após a vivência da aula na escola. Para Bittar (2017), o professor deve conhecer o livro didático (sistematização de conteúdos e atividades) para usá-lo de maneira a propiciar a aprendizagem para os estudantes. Dessa forma, podendo produzir sequências didáticas com o seu suporte e não só propor atividades isoladas.

Outro ponto destacado é sobre o professor conhecer, por meio do uso desse material, possíveis lacunas/dificuldades de conhecimentos por parte dos estudantes, seja por não produzir as atividades ou por alegar o não entendimento do conceito e conteúdo abordado na sala de aula. Portanto, tanto para o professor quanto para o estudante, "o livro didático utilizado por eles é uma das fontes a serem consultadas. Não é a única, porém, como o Livro Didático é o principal 
material utilizado pelo professor no preparo de suas aulas, seu estudo permite, entre outros, certa aproximação com o que é ensinado pelo professor" (BITTAR, 2017, p. 365-366).

Corroborando a ideia de Bittar (2017), Pachêco e Silva (2019) frisam que, no ensino público brasileiro, os estudantes e professores têm acesso, de maneira gratuita, aos livros didáticos, sendo, por esse motivo, muitas vezes, o único recurso usado pelo professor no processo de ensino dos conteúdos. Dessa forma, é, para a sociedade, um recurso útil por contribuir para a educação. Além disso, "a riqueza de informações que deles podemos extrair e resgatar justifica o seu uso em várias áreas das Ciências Humanas e Sociais porque possibilita ampliar o entendimento de objetos cuja compreensão necessita de contextualização histórica e sociocultural" (SÁ-SILVA; ALMEIDA; GUIDANI, 2009, p. 2).

Os livros didáticos sugerem, ainda, recomendações para os professores se apoiarem e lecionar conteúdo(s), situações-problema para os estudantes resolverem em grupo ou individualmente, fatos da História da Matemática, entre outros elementos. Dessa forma, trata-se de um recurso que favorece a reflexão na intenção de propiciar aprendizagem. Nesse sentido, "por serem muito usuais no ambiente da sala de aula, os livros didáticos tornaram-se alvos de pesquisas científicas que vislumbram olhar para esses materiais, de maneira crítica, analisandoos como são propostos os diversos conceitos, conteúdos e atividades matemáticas" (PACHÊCO; SILVA, 2019, p. 1).

O livro didático, portanto, é um recurso relevante para ser usado no ambiente da sala de aula. Essa ideia é destacada por diversos pesquisadores (CARVALHO; LIMA, 2010; BITTAR, 2017; PACHÊCO; SILVA, 2019) que potencializam o uso desse material para a construção de conhecimento, apesar de ser um recurso estático.

Entende-se que o livro didático é um material com muitos elementos (sistematização de conceitos, conteúdos, atividades, propostas metodológicas, etc.) que, ao serem integradas na sala de aula pelo professor, podem promover a aprendizagem. Esses materiais propiciam, ainda, a reflexão de que pesquisadores, professores e estudantes podem discutir elementos pertinentes para melhorá-los e/ou corroborar as informações apresentadas pelo(s) autor(es) ao longo do texto disponibilizado para o processo de ensino e de aprendizagem. Assim sendo, é possível destacar que analisar livros didáticos é potencializar a relevância desses materiais para o processo de ensino e de aprendizagem na Educação Básica, por isso, é fundamental conhecer sua realidade (propostas de ensino dos distintos conteúdos e atividades) para que esse material continue sendo aprimorado como uma ferramenta agradável e essencial para a construção do conhecimento. Sobre isso, "é relevante discutir, ainda, que cada autor de Livro Didático pensa e aborda o conteúdo sistematizado de maneira diferente um do outro, por isso é essencial sempre se aperfeiçoar nos estudos de análises sobre o Livro Didático" (PACHÊCO; SILVA, 2019, p. 6). 


\section{Procedimentos metodológicos}

Esta pesquisa analisou três coleções de livros didáticos dos anos iniciais do Ensino Fundamental. A opção por elas se deu porque essas obras foram aprovadas pelo PNLD 2019, seguem as recomendações da BNCC (BRASIL, 2017) e são as únicas de Matemática que estão disponíveis, de forma gratuita, para consulta em formato on-line na página do PNLD 2019 do site e-docente ${ }^{1}$ para o público (professor, estudante, pais, etc.). Essas informações estão no Quadro 1.

Quadro 1 - Coleções de livros didáticos disponibilizados on-line no e-docente.

\begin{tabular}{|c|c|c|c|c|c|c|}
\hline Coleção & Autor & Título & Editora & Edição & Local & Ano \\
\hline C1 & $\begin{array}{c}\text { Júlio Cesar Augustus } \\
\text { de Paula Santos }\end{array}$ & Vem Voar & Scipione & $1^{\text {a }}$ & São Paulo & 2017 \\
\hline C2 & Eliane Reame & Ligamundo & Saraiva & $1^{\text {a }}$ & São Paulo & 2017 \\
\hline C3 & Luiz Roberto Dante & Ápis & Ática & $3^{\text {a }}$ & São Paulo & 2017 \\
\hline
\end{tabular}

Fonte: Elaborado pelos autores (2020).

Por investigar livros didáticos, o presente estudo é de caráter documental. Concorda-se que "[...] sempre que uma pesquisa se utiliza apenas de fontes documentais (livros, revistas, documentos legais, arquivos em mídia eletrônica), diz-se que a pesquisa possui estratégia documental." (APPOLINÁRIO, 2009, p. 85).

Buscou-se analisar a presença da História da Matemática nos livros didáticos e, para isso, adotou-se, como procedimentos para discussão dos resultados, a perspectiva da Análise de Conteúdo de Bardin (1977). Essa estratégia é definida como:

Um conjunto de técnicas de análise das comunicações, visando obter, por procedimentos objetivos e sistemáticos de descrição do conteúdo das mensagens, indicadores (quantitativos ou não) que permitam a inferência de conhecimentos relativos às condições de produção/recepção destas mensagens (BARDIN, 1977, p. 42).

A análise do conteúdo, de acordo com Bardin (1977), consiste em três polos (Pré-análise, Exploração do Material, e Tratamento dos resultados obtidos e interpretação). A "Pré-análise" consiste na organização da análise do conteúdo. Qual material vai ser explorado para estudo? De modo geral, nesse primeiro momento, aborda-se a noção de como será a organização dos dados a fim de construir o corpus da pesquisa. O "corpus é o conjunto dos documentos tidos em conta para serem submetidos aos procedimentos analíticos" (BARDIN, 1977, p. 96). A Pré-análise é vivenciada por meio das seguintes etapas: a) leitura flutuante ${ }^{2}$; b) escolha dos documentos (regra da exaustividade; regra da representatividade; regra da homogeneidade e regra da pertinência); c) a formulação das hipóteses e dos objetivos; d) a referenciação dos índices e elaboração de indicadores e e) a preparação do material. A "Exploração do material", segundo polo de Bardin (1977), está apoiada pelas codificações, decomposição ou enumeração a partir de regras

${ }^{1}$ Disponível em: https://edocente.com.br/edital/pnld-2019. Acesso em: 11 nov. 2020.

2 É "a primeira atividade [a qual] consiste em estabelecer contacto com os documentos a analisar e em conhecer o texto deixando-se invadir por impressões e orientações" (BARDIN, 1997, p. 96). 
estabelecidas. Por fim, o "Tratamento dos resultados obtidos e interpretação" se constitui como o momento em que é possível estabelecer relações entre as informações e interpretar os dados para validar os resultados. Adotou-se esses momentos para analisar os resultados desta pesquisa.

\section{Análises e discussões dos resultados}

A sistematização dos resultados, nesta seção, seguiu as etapas estabelecidas por Bardin (Pré-análise, Exploração do Material, e Tratamento dos resultados obtidos e interpretação).

Para atender a proposta de investigação (analisar a abordagem da História da Matemática em livros didáticos dos anos iniciais do Ensino Fundamental), optou-se por três coleções de livros didáticos, como apresentado no Quadro 1 na seção anterior. Cada coleção (C1, C2 e C3) contém 5 exemplares (do $1^{\circ}$ ao $5^{\circ}$ ano), com isso, foram analisados um total de 15 livros didáticos. Por ter um vasto campo de material para analisar e discutir os resultados, realizou-se uma leitura flutuante nas coleções adotadas dos livros didáticos, de modo a demarcar o universo da pesquisa (capítulos dos livros didáticos). Por meio da associação entre esses dois momentos (leitura flutuante e análise dos documentos), o corpus da pesquisa foi constituído pelos 15 livros dos anos iniciais do Ensino Fundamental. Neles, foi investigada, em distintos capítulos, a História da Matemática.

Após definir "o campo do corpus [...], é preciso terem-se em conta todos os elementos desse corpus" (BARDIN, 1977, p. 97). Com isso, nesse momento, voltou-se a realizar uma nova leitura flutuante nas três coleções para identificar os elementos (Conteúdo, Atividades e Imagens) presentes nos livros didáticos que abordam a História da Matemática. Realizou-se essa vivência (regra da exaustividade) para formar um segundo corpus mais consistente e definido para a posterior análise dos seus elementos.

Embora os resultados dessa investigação, expostos a seguir, sejam provenientes do total de 15 livros didáticos, a análise desta pesquisa não recorreu à regra da representatividade, ou seja, não se ancorou em dados por meio de amostras. O material analisado, tanto para escolha quanto para caracterização dos resultados, foi submetido ao mesmo processo de avaliação, isto é, todos eles foram verificados de forma homogênea e contemplam o objetivo geral da pesquisa, sendo, portanto, adequados para esse estudo, atendendo a regra de pertinência.

Depois de definido o corpus, para analisá-lo foram utilizadas, como instrumentos, as atividades, imagens e descrições que contemplavam aspectos condizentes a elementos da História da Matemática. O Quadro 2 sintetiza os instrumentos que compuseram o corpus da pesquisa e que, posteriormente, foram analisados para compor os resultados. 
Quadro 2 - Instrumentos que integram o corpus da pesquisa.

\begin{tabular}{|c|c|}
\hline Instrumento & Características \\
\hline Conteúdo & $\begin{array}{c}\text { Descrições que potencializem que os conhecimentos matemáticos } \\
\text { são provenientes da necessidade do homem, em distintas épocas e } \\
\text { culturas, para atender a demanda de sua vida social ou/e acadêmica }\end{array}$ \\
\hline Atividades & $\begin{array}{c}\text { Enunciados de exercícios e exemplos, envolvendo elementos } \\
\text { históricos, que buscam aprofundar/avaliar a compreensão de } \\
\text { conteúdos ou da História da Matemática }\end{array}$ \\
\hline Imagens & $\begin{array}{c}\text { Ilustrações que contemplem elementos históricos. Por exemplo, } \\
\text { pastores contando o quantitativo de ovelhas com o uso de pedras, } \\
\text { ideia essa, associada à contagem }\end{array}$ \\
\hline
\end{tabular}

Fonte: Elaborado pelos autores (2020).

Uma hipótese levantada é a de que existem poucos elementos históricos abordados nos livros didáticos dos anos iniciais do Ensino Fundamental. Essa ideia emergiu a partir de estudos anteriores (LOPES; ALVES, 2013; PACHÊCO; SILVA; PACHÊCO, 2018), realizados nos anos finais do Ensino Fundamental e do Ensino Médio, respectivamente, que mostraram pouca abordagem sobre essa temática em livros didáticos.

As análises dos conteúdos, atividades e imagens descritas a seguir foram utilizadas para a compreensão dos resultados desta pesquisa e foram mediados através da referenciação dos índices e da elaboração de indicadores. Realizada a parte da Pré-análise, iniciou-se a Exploração do Material em paralelo com o Tratamento dos resultados obtidos e interpretação. É nesse momento em que o corpus vai ser estudado de maneira detalhada e aprofundada, por meio dos instrumentos que constituem o corpus, com o objetivo de que os resultados sejam "tratados de maneira a serem significativos (falantes) e válidos" (BARDIN, 1977, p. 101).

De modo a tentar averiguar a hipótese inicial, a preparação do material ${ }^{3}$ se deu de forma qualitativa. Assim sendo, de acordo com os instrumentos que integram o corpus, foram desenvolvidos três procedimentos para codificar os dados. Eles estão expressos a seguir.

1) Analisar, nas coleções dos livros didáticos, os conteúdos que abordam História da Matemática. Para coletar esses resultados, foram analisados todos os capítulos dos livros didáticos. Considerou-se, nesse sentido, elementos que destacassem que os conhecimentos matemáticos foram criados pelo homem. Os resultados estão expressos no Quadro 3.

Quadro 3 - Conteúdos propostos nos livros didáticos que abordam História da Matemática.

\begin{tabular}{|c|c|c|}
\hline Coleções & Livros didáticos & Conteúdos \\
\hline \multirow{4}{*}{ C1 } & $1^{\circ}$ Ano & Não possui \\
\cline { 2 - 3 } & $2^{\circ}$ Ano & Números (símbolos do sistema de numeração egípcio) \\
\cline { 2 - 3 } & $3^{\circ}$ Ano & $\begin{array}{c}\text { Medidas de comprimento e Números } \\
\text { Sistema de numeração egípcio }\end{array}$ \\
\cline { 2 - 3 } & $4^{\circ}$ Ano & Não possui \\
\cline { 2 - 3 } & $5^{\circ}$ Ano & Números (sistema de numeração romano) \\
\hline
\end{tabular}

${ }^{3}$ É o momento "antes da análise propriamente dita, o material reunido deve ser preparado. Trata-se de uma preparação material e, eventualmente, de uma preparação formal” (BARDIN, 1977, p. 100). 


\begin{tabular}{|c|c|c|}
\hline \multirow{5}{*}{$\mathrm{C} 2$} & $1^{\circ} \mathrm{Ano}$ & Não possui \\
\hline & $2^{\circ}$ Ano & Medida de comprimento (medindo com as mãos) \\
\hline & $3^{\circ} \mathrm{Ano}$ & Distintas unidades de medidas de comprimento \\
\hline & $4^{\circ} \mathrm{Ano}$ & Não possui \\
\hline & $5^{\circ}$ Ano & Número (sistema de numeração romano) \\
\hline \multirow{5}{*}{ C3 } & $1^{\circ} \mathrm{Ano}$ & Números (quantidade até 10) \\
\hline & $2^{\circ}$ Ano & Números (um pouco da história dos números) \\
\hline & $3^{\circ}$ Ano & $\begin{array}{l}\text { Números até } 1000 \text { (um pouco da história) } \\
\text { Medida do tempo }\end{array}$ \\
\hline & $4^{\circ} \mathrm{Ano}$ & $\begin{array}{l}\text { Sistema de numeração (um pouco da história dos números, } \\
\text { sistemas de numeração egípcio, maia, romano e decimal) }\end{array}$ \\
\hline & $5^{\circ} \mathrm{Ano}$ & Adição e subtração com números naturais (Nicolau Copérnico) \\
\hline
\end{tabular}

Fonte: Dados da pesquisa (2020).

Verificou-se, como é possível observar no Quadro 3, que, dentre os blocos de conteúdos (Números e Operações, Espaço e Forma, Grandezas e Medidas, e Tratamento da Informação) propostos pelos PCN (BRASIL, 1997), o que contém mais aspectos históricos da Matemática é o dos Números e operações, seguida pelo das Grandezas e Medidas. Nesse sentido, é possível observar que o conteúdo mais abordado nas coleções de livros didáticos ( $C 1, C 2$ e C3) é o dos números. Para explorar esse conhecimento matemático, os autores dos livros didáticos abordam distintos sistemas de numeração (egípcio, babilônico, chinês, maia, hindu-arábico, etc.), identificando suas semelhanças e diferenças para o contexto da Matemática. Esse resultado mostra que, ao longo dos anos, os números foram representados por diferentes símbolos e por distintas culturas. O que corrobora o que propõem os PCN sobre a História da Matemática, isto é, que ela surgiu mediante "diferentes origens e contextos, motivadas por problemas de ordem prática (divisão de terras, cálculo de créditos), por problemas vinculados a outras ciências (Física, Astronomia), bem como por problemas relacionados a investigações internas à própria Matemática" (BRASIL, 1997, p. 32).

No Brasil, o sistema de numeração denomina-se sistema de numeração decimal (base 10). Uma diferença entre as representações dos sistemas de numeração egípcio e decimal é que "no sistema de numeração egípcio a ordem em que escrevemos os símbolos não altera o número, pois o valor do símbolo não depende da posição que ele ocupa, diferentemente do sistema de numeração decimal" (SANTOS, 2017, p. 74). Outra distinção que cabe ressaltar é que enquanto, no sistema de numeração egípcio, observa-se a existência da repetição de um mesmo símbolo para expressar o número de 1 a 9, no sistema romano isso não ocorre, pois nele é contemplada a importância do sistema posicional. Por exemplo, a abordagem deste conteúdo traz para o estudante a ideia de que o I na frente ou atrás de $X$ tem significado distinto, ou seja, IX $=9$ enquanto que $X I=11$. Por isso, é interessante "estabelecer comparações entre os conceitos e processos matemáticos do passado e do presente, o professor tem a possibilidade de desenvolver atitudes e valores mais favoráveis do estudante diante do conhecimento matemático" (BRASIL, 1997, p. 34). 
Sobre a abordagem da medição nos livros didáticos, os autores disponibilizam que é essencial destacar, por exemplo, que, no Egito, as "civilizações foram se desenvolvendo. Uma tentativa de padronização usava as medidas do corpo do rei, porém essa também não se mostrou uma padronização eficiente" (SANTOS, 2017, p. 70). Verificou-se, ainda, que todas as coleções de livros didáticos analisadas se apoiam na ideia de medida e instrumentos dos egípcios, usados na antiguidade para abordar elementos da História da Matemática. Identificou-se que o objeto matemático explorado pelos autores é o comprimento, o qual era medido por meio das partes do corpo do rei (pé, mão, braço, etc.). Na época, adotou-se o comprimento das partes do corpo do rei como unidade de medida por ele centrar o "chefe" da população.

Dentre as coleções, apenas a C3 propõe aspectos históricos para todos os anos escolares. Observou-se que, de modo semelhante, na C1 e na C2, nos livros direcionados ao $1^{\circ}$ e $4^{\circ}$ anos do Ensino Fundamental não foram identificadas descrições (elementos históricos) relacionadas aos conteúdos. Pelo "silêncio" dessas obras, no que tange à abordagem de elementos históricos no $1^{\circ}$ e $4^{\circ}$ anos, há indicação de um foco na compreensão dos seus conteúdos e não na sua contextualização com o desenvolvimento histórico.

Após a verificação de quais conteúdos os autores destacam elementos históricos, mostram-se, a seguir, os resultados referentes à existência de atividades que abordam elementos históricos.

2) Analisar a existência de atividades que contemplam elementos históricos da Matemática. Esse momento foi demarcado pela leitura de todos os enunciados das atividades, sendo identificado se, nelas, constavam elementos (sistemas de numeração das antigas culturas, medidas dos povos antigos, etc.) que correspondiam a aspectos históricos da matemática. Os resultados desse momento estão no Quadro 4.

Quadro 4 - Contexto e quantidade de atividades por livro didático.

\begin{tabular}{|c|c|c|c|}
\hline Coleção & Livro didático & Contexto da atividade & $\begin{array}{c}\text { Quantitativo de } \\
\text { atividades }\end{array}$ \\
\hline \multirow{4}{*}{ C1 } & $1^{\circ}$ Ano & Não possui & 0 \\
\cline { 2 - 4 } & $2^{\circ}$ Ano & Escrita do antigo Egito (Hieróglifo) & 2 \\
\cline { 2 - 4 } & $3^{\circ}$ Ano & $\begin{array}{c}\text { Representar números naturais no sistema } \\
\text { de numeração egípcio }\end{array}$ & 4 \\
\cline { 2 - 4 } & $4^{\circ}$ Ano & Não possui & 0 \\
\hline \multirow{4}{*}{ C2 } & $5^{\circ}$ Ano & $\begin{array}{c}\text { Representar números naturais por meio } \\
\text { do sistema romano }\end{array}$ & 6 \\
\cline { 2 - 4 } & $1^{\circ}$ Ano & Não possui & 0 \\
\cline { 2 - 4 } & $2^{\circ}$ Ano & Medição com as mãos & 4 \\
\cline { 2 - 4 } & $3^{\circ}$ Ano & Medidas no dia a dia & 3 \\
\cline { 2 - 4 } & $4^{\circ}$ Ano & Não possui & 4 \\
\hline \multirow{3}{*}{ C3 } & $5^{\circ}$ Ano & Escrever números naturais usando \\
& $1^{\circ}$ snómbolos romanos & Representação de quantidades & 2 \\
\cline { 2 - 4 } & $2^{\circ}$ Ano & Registrar quantidades (algarismos) & 2 \\
\cline { 2 - 4 } & $3^{\circ}$ Ano & História do número e medida do tempo & 2 \\
\hline
\end{tabular}




\begin{tabular}{|c|c|c|c|}
\hline & $4^{\circ}$ Ano & $\begin{array}{c}\text { Escrever números naturais por meio do } \\
\text { sistema de numeração (egípcio, maia, } \\
\text { romano e decimal) }\end{array}$ & 10 \\
\cline { 2 - 4 } & $5^{\circ}$ Ano & $\begin{array}{c}\text { Expondo Nicolau Copérnico enquanto } \\
\text { astrônomo e matemático }\end{array}$ & 1 \\
\hline
\end{tabular}

Fonte: Dados da pesquisa (2020).

De modo comparativo, em relação ao quantitativo de atividades presentes nas coleções analisadas, verificou-se que a C3 propõe 16 atividades, a C1 propõe um total de 12 atividades e a C2 propõe 11 atividades. Além disso, ao analisar o corpus da pesquisa, identificou-se com mais ênfase dois tipos de atividades: representar números naturais usando sistema de numeração (egípcio, maia e romano), e vice e versa; realizar medições ancoradas em práticas da civilização egípcia (pé, mão, etc.).

Em consonância com o que foi observado na análise anterior, verificou-se que a C1 e a C2 não possuem atividades relacionadas à História da Matemática nos livros correspondentes ao $1^{\circ} \mathrm{e}$ $4^{\circ}$ anos do Ensino Fundamental, reforçando a perspectiva de que estes livros didáticos optam por uma apresentação que não faz uso da contextualização histórica dos conteúdos abordados.

Outro contraste em relação aos resultados trata de que, na $\mathrm{C} 1$ e na $\mathrm{C} 2$, o livro correspondente ao $5^{\circ}$ ano do Ensino Fundamental é o que detém um maior quantitativo de atividades, 6 e 4, respectivamente, enquanto a C3 possui apenas 1 atividade para o referido ano. Os autores das coleções C1 e C2, aparentemente, compreendem que é necessária uma bagagem maior de conteúdo para a apresentação de perspectivas da História da Matemática. Nesse sentido, a coleção C3 reforça essa perspectiva ao se observar uma maior abordagem destes elementos no livro direcionado ao $4^{\circ}$ ano (10 atividades).

Por meio desses resultados, observou-se a pouca exploração de atividades nos livros didáticos analisados para o trabalho com a matemática no ambiente da sala de aula pela temática da História da Matemática. Esses dados, portanto, sinalizam para um pouco tratamento dado à História da Matemática nos anos iniciais do Ensino Fundamental. O que corrobora os resultados encontrados nas pesquisas de Lopes e Alves (2013) realizada no Ensino Médio, e Pachêco, Silva e Pachêco (2018) desenvolvida no Ensino Fundamental, anos finais.

Apesar dos documentos de orientações curriculares, PCN (BRASIL, 1997) e BNCC (BRASIL, 2018), destacarem a relevância da História da Matemática ser vivenciada nas aulas de matemática, resultados como o do presente estudo, ao apontarem para a pouca exploração da abordagem de elementos históricos, são essenciais para se discutir e entender o porquê dessa ocorrência, visto que essa temática é obrigatória para aprovação das coleções dos livros didáticos pelo PNLD.

Entende-se que a discussão da devida temática desde os anos iniciais do Ensino Fundamental possa fomentar os estudantes a compreenderem que a matemática, por ser uma criação do homem, seja ainda mais interessante de se estudar, tendo em vista sua utilidade no 
contexto acadêmico e social. Essa realidade, propiciada pelo trabalho com a História da Matemática, é interessante no processo de ensino e de aprendizagem na Educação Básica durante as aulas de matemática e é apontada por alguns pesquisadores (CURY; MOTTA, 2008; MIGUEL; MIORIM, 2011; LOPES; ALVES, 2013; LOPES; FERREIRA, 2013; PEREIRA, 2016; PACHÊCO; SILVA; PACHÊCO, 2018). Investigou-se, ainda, as imagens das atividades e dos conteúdos que davam suporte à exploração da História da Matemática no corpus da pesquisa. Esse momento compôs mais uma etapa dos resultados.

3) Analisar, nos capítulos dos livros didáticos, imagens que estejam relacionadas ao conteúdo por meio de descrição de aspectos históricos da Matemática. Analisou-se as imagens, nesse momento, que fizessem relação ou menção ao surgimento de conhecimentos matemáticos. Os resultados estão expostos no Quadro 5. Optou-se por analisar figuras, compondo o corpus, porque elas estão, na maioria das vezes, associadas às descrições históricas de modo a ilustrar a situação descrita para o usuário do livro didático.

Quadro 5 - Figuras contempladas por conteúdo explorado.

\begin{tabular}{|c|c|c|c|c|}
\hline \\
\hline Conteúdos & Imagens & C1 & $\mathrm{C2}$ & C3 \\
\hline \multirow{4}{*}{$\begin{array}{l}\text { Números (símbolos do } \\
\text { sistema de numeração } \\
\text { egípcio) }\end{array}$} & Registros em papéis & $\mathrm{X}$ & - & $\mathrm{X}$ \\
\hline & Gravura em pedras & $\mathrm{X}$ & - & $\mathrm{X}$ \\
\hline & Algarismos & $\mathrm{X}$ & - & $\mathrm{X}$ \\
\hline & Povo egípcio & $\mathrm{X}$ & - & - \\
\hline \multirow{3}{*}{$\begin{array}{l}\text { Números (sistema de } \\
\text { numeração romano) }\end{array}$} & Relógio de parede & $\mathrm{X}$ & - & $\mathrm{X}$ \\
\hline & $\begin{array}{c}\text { Algarismos expressos em } \\
\text { quadros ou papel }\end{array}$ & $X$ & $X$ & $x$ \\
\hline & Povo romano & - & $\mathrm{X}$ & $\mathrm{X}$ \\
\hline \multirow{4}{*}{ Contagem } & Nós em cordas & - & - & $\mathrm{X}$ \\
\hline & Pedras & - & - & $\mathrm{X}$ \\
\hline & Gravetos & - & - & $X$ \\
\hline & Ossos & - & - & $\mathrm{X}$ \\
\hline $\begin{array}{l}\text { Medida de } \\
\text { comprimento }\end{array}$ & $\begin{array}{l}\text { Partes do corpo do rei (pés, } \\
\text { mãos, dedos, braço, etc.) }\end{array}$ & $X$ & 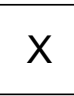 & - \\
\hline Matemática & Matemáticos & - & - & $x$ \\
\hline
\end{tabular}

Fonte: Dados da pesquisa (2020).

De modo a ilustrar as informações expostas no Quadro 5, a seguir, expõe-se a Figura 1. É possível observar, por exemplo, a presença de representações de fatos históricos matemáticos da contagem unitária (por meio dos traços presentes no osso, dos nós na corda, dos traços na rocha, do quantitativo de gravetos e pedras), e o número 6, representado nos sistemas de numeração egípcio, romano e maia. Em cada sistema de numeração existe um personagem correspondente de cada cultura, segundo a representação do seu sistema numérico. 
Figura 1 - Representação de fatos históricos por meio de figuras.

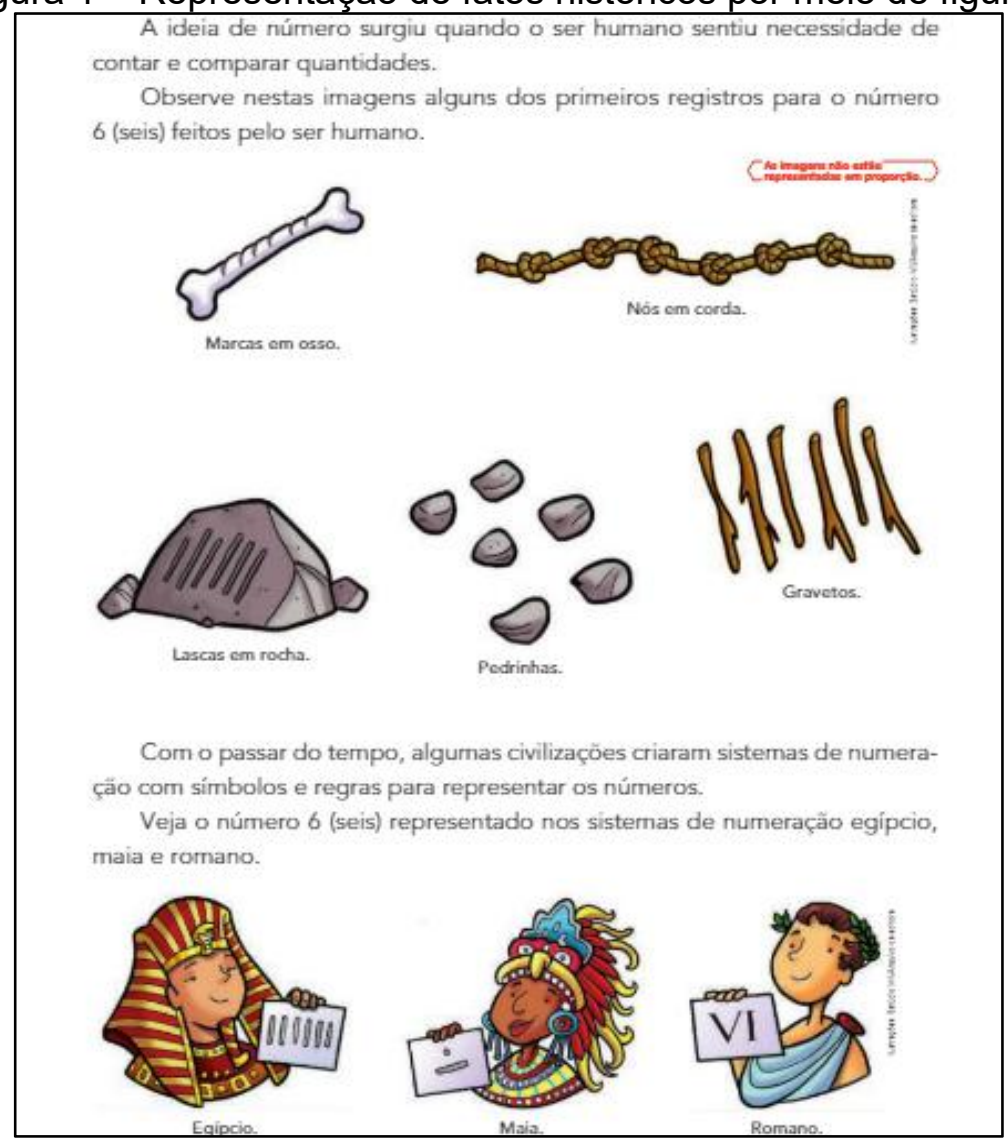

Fonte: Dante (2017, p. 15).

Além dessas opções de imagens que estão relacionadas diretamente aos conteúdos, vale ressaltar que os livros didáticos apresentam, também, personagens emblemáticos que contribuíram para o desenvolvimento dos conhecimentos matemáticos ao longo da história. Nesses casos, por exemplo, os autores dos livros didáticos expõem uma pequena biografia que ressalta a contribuição deixada por eles(as) no campo da Matemática.

De acordo com Bardin (1977) o "Tratamento dos Resultados e Interpretação da Análise de Conteúdo" é uma estratégia que possibilita realizar a "operação de classificação de elementos constitutivos de um conjunto, por diferenciação e, seguidamente, por reagrupamento segundo o género (analogia), com os critérios previamente definidos" (p. 117). Desse modo, é necessário ressaltar que os resultados apresentaram que, entre os variados conteúdos propostos para o processo de ensino e de aprendizagem da matemática do $1^{\circ}$ ao $5^{\circ}$ ano do Ensino Fundamental, a ênfase da História da Matemática está centrada na discussão sobre números (sistemas de numerações), contagem (em pequenas quantidades) e medições (usadas pelos egípcios na antiguidade). Quanto às atividades, as análises mostraram que, nas três coleções de livros didáticos utilizadas nesta pesquisa, existem poucas atividades que façam associação com a História da Matemática. Por fim, verificou-se que, em C1, C2 e C3, as representações associadas às descrições da História da Matemática são semelhantes, por exemplo: figura de mão, pé ou braço para representar que a parte do corpo do rei era utilizada na abordagem das diferentes 
perspectivas históricas de processos de medição. Assim, é possível perceber que a hipótese de que existem poucos elementos históricos abordados nos livros didáticos dos anos iniciais do Ensino Fundamental foi validada. Com isso, os resultados desta pesquisa reafirmam os resultados dos estudos de Lopes e Alves (2013) e Pachêco, Silva e Pachêco (2018).

Apesar de os resultados da presente pesquisa apontarem para um tratamento menor em relação à História da Matemática, concorda-se com os estudos de Cury e Motta (2008), Miguel e Miorim (2011), Lopes e Alves (2013), Lopes e Ferreira (2013), Pereira (2016) e Pachêco, Silva e Pachêco (2018) por concluírem que a História da Matemática é essencial para o processo de ensino e da aprendizagem dos conhecimentos matemáticos. A História da Matemática permite explorar como ocorreu o surgimento dos conhecimentos matemáticos, quais foram suas adaptações ao longo dos anos e como encontra-se atualmente. Sendo, portanto, um recurso útil para ser usado pelo professor no ambiente da sala de aula. Além disso, potencializa o papel do homem na construção do saber matemático, elucidando sua presença na vida social do ser humano.

Outro resultado importante a ser destacado desta pesquisa é que ela potencializa o livro didático enquanto recurso relevante para o trabalho com conteúdos de Matemática no ambiente da sala de aula. Sendo um material para o professor planejar suas aulas e promover o processo de aprendizagem, caso existam elementos históricos da Matemática, "o professor pode usar a História da Matemática como um recurso para tornar suas aulas mais dinâmicas, com o intuito de proporcionar a curiosidade nos alunos sobre a origem desses conhecimentos na antiguidade, seu desenvolvimento e a atual" (PACHÊCO; SILVA; PACHÊCO, 2018).

No contexto escolar, portanto, a História da Matemática pode ser mediada por meio dos livros didáticos. Assim sendo, o professor deve procurar metodologias que potencializem a relevância dessa discussão no ambiente da sala de aula para propiciar que esse conhecimento seja fruto de várias culturas e que vem se modificando ao longo dos anos, pois não é uma ciência perfeita (pronta).

\section{Considerações finais}

Esta pesquisa, ao investigar a História da Matemática em livros didáticos dos anos iniciais do Ensino Fundamental, integra o conjunto de estudos voltados para o âmbito da Educação Matemática.

Os livros didáticos, para serem aprovados pelo PNLD, como destacam os autores Pachêco, Silva e Pachêco (2018), devem conter elementos históricos da Matemática. Os resultados mostraram que existem poucas menções históricas relacionadas aos conhecimentos matemáticos nas coleções analisadas (C1, C2 e C3). A presente pesquisa, ao apontar como resultados que as coleções analisadas possuem pouca abordagem histórica para os anos iniciais do Ensino 
Fundamental, corrobora as discussões levantadas por Pachêco, Silva e Pachêco (2018) e Lopes e Alves (2013) quanto aos anos finais desta etapa do ensino.

Por meio da realidade desta análise, emergiram as seguintes inquietações: por que o bloco dos Números e Operações é o mais abordado com aspectos históricos nos livros didáticos do $1^{\circ}$ ao $5^{\circ}$ ano do Ensino Fundamental? Essa realidade é a mesma nas outras etapas (anos finais do Ensino Fundamental e Ensino Médio) de escolaridades da Educação Básica? Mesmo sabendo que esse conhecimento foi produzido pelos homens ao longo dos anos, existe alguma unidade temática da BNCC (BRASIL, 2018) que não possui elementos que correspondam à História da Matemática? Esses são alguns questionamentos, entre muitos, que podem ser investigados sobre a temática da História da Matemática com o objetivo de contribuir para o conjunto de estudos de âmbito brasileiro que versam seu olhar sobre a devida temática.

Espera-se que os resultados desta investigação possam levar alguns pesquisadores, professores e estudantes a refletirem ainda mais sobre a presença de aspectos históricos presentes nos livros didáticos. Essa trajetória, ao possibilitar a observação das mudanças e da evolução do conhecimento matemático desde a antiguidade aos dias recentes, potencializa o papel do homem na construção da Matemática (CURY; MOTTA, 2008; MIGUEL; MIORIM, 2011; LOPES; ALVES, 2013; LOPES; FERREIRA, 2013; PEREIRA, 2016; PACHÊCO; SILVA; PACHÊCO, 2018).

Entender como o conhecimento matemático surgiu e desenvolveu-se até os dias atuais é essencial para construir o conhecimento Matemático no processo de ensino e de aprendizagem no ambiente da sala de aula.

\section{Referências}

APPOLINÁRIO, F. Dicionário de metodologia científica: um guia para a produção do conhecimento científico. 1. ed. São Paulo, Atlas, 2009.

BALESTRI, R. D.; CYRINO, M. C. C. T.; SAVIOLI, Â. M. P. D. A participação da história da matemática na formação de professores de matemática na óptica de professores/pesquisadores. In: ENCONTRO BRASILEIRO DE ESTUDANTES DE PÓS-GRADUAÇÃO EM EDUCAÇÃO MATEMÁTICA - EBRAPEM, 12, 2008, Rio Claro. Anais [...]. Rio Claro: UNESP, 2008. Disponível em: http://www2.rc.unesp.br/eventos/matematica/ebrapem2008/upload/345-1-A-

GT4 balestri tc.pdf. Acesso em: 08 set. 2020.

BARDIN, L. Análise de conteúdo. Lisboa: Edições 70, 1977.

BITTAR, M. A Teoria Antropológica do Didático como ferramenta metodológica para análise de livros didáticos. Zetetiké. Campinas, SP, v. 25, n. 3, p. 364-387, set./dez. 2017. DOI: https://doi.org/10.20396/zet.v25i3.8648640.

BRASIL. Base Nacional Curricular Comum - BNCC. Brasília, 2018, p. 600. Disponível em: http://basenacionalcomum.mec.gov.br/images/BNCC EI EF 110518 versaofinal site.pdf. Acesso em: 13 set. 2020. 
BRASIL. Secretária de Educação Fundamental. Parâmetros curriculares nacionais: Matemática. Brasília: MEC/SEF,1997. 142 p. Disponível em:

http://portal.mec.gov.br/seb/arquivos/pdf/livro03.pdf. Acesso em: 07 set. 2020.

BRASIL. Secretária de Educação Fundamental. Parâmetros curriculares nacionais: Matemática. Brasília: MEC/SEF,1998. 148 p. Disponível em:

http://portal.mec.gov.br/seb/arquivos/pdf/matematica.pdf. Acesso em: 09 set. 2020.

CARVALHO, J. B. P.; LIMA, P. F. Escolha e uso do livro didático. In: CARVALHO, João Bosco Pitombeira de. Coleção Explorando o Ensino: Matemática, v. 17. Brasília: MEC, 2010, p. 15-30.

CURY, H. N.; MOTTA, C. E. M. Histórias e estórias da matemática: uma entrevista com Heron nos dias atuais. In: CARVALHO, Luiz Mariano; CURY, Helena Noronha; MOURA, Carlos; FOSSA, John; GIRALDO, Victor. (Orgs.). História e tecnologia no ensino da Matemática. Rio de Janeiro: Ciência Moderna, 2008. p. 1-14.

DANTE, L. R. Ápis Matemática. Coleção de Livros Didáticos do $1^{\circ}$ ao $5^{\circ}$ ano do Ensino Fundamental. 3. ed., São Paulo: Ática, 2017.

LOPES, L. S.; ALVES, A. M. M. A história no livro didático de matemática. In: CONGRESSO INTERNACIONAL DE ENSINO DA MATEMÁTICA, VI, 2013, Canoas. Anais [...]. Canoas: ULBRA, 2013, p. 1-14. Disponível em:

http://www.conferencias.ulbra.br/index.php/ciem/vi/paper/viewFile/956/924. Acesso em: 04 set. 2020.

LOPES, L. S.; FERREIRA, A. L. A. Um olhar sobre a história nas aulas de matemática. ABAKÓS, Belo Horizonte, v. 2, n. 1, p. 75-88, 2013. DOI: https://doi.org/10.5752/P.2316-9451.2013v2n1p75.

MIGUEL, A.; MIORIN, M. Â. História na Educação Matemática: propostas e desafios. 3. ed. Belo Horizonte: Autêntica Editora, 2011.

OLIVEIRA, S. K. I. A história da matemática nos anos iniciais: Uma ferramenta necessária para ensino. 2016. 25 f. Orientador: Robson William Potier. Trabalho de Conclusão de Curso (Curso de Pedagogia) - Universidade Federal do Rio Grande do Norte, Macau, 2016. Disponível em:

https://monografias.ufrn.br/jspui/bitstream/123456789/4505/3/A\%20hist\%C3\%B3ria\%20da\%20mat em\%C3\%A1tica Artigo 2016.pdf. Acesso em: 10 set. 2020.

PACHÊCO, F. F. F.; SILVA, A. S. Atividades sobre comparação de áreas presentes em uma coleção de livros didáticos do $6^{\circ}$ ao $9^{\circ}$ ano do Ensino Fundamental: um olhar sob os aspectos numéricos e geométricos. In: CONGRESSO NACIONAL DE EDUCAÇÃO, VI, 2019, Fortaleza. Anais [...]. Fortaleza: Editora Realize, 2019. p.1-12. Disponível em: https://editorarealize.com.br/editora/anais/conedu/2019/TRABALHO EV127 MD1 SA13 ID2536 08082019145411.pdf. Acessado em 11 set. 2020.

PACHÊCO, F. F. F.; SILVA, A. S.; PACHÊCO, G. F. Aspectos hitóricos abordados em livros didáticos de matemática dos anos finais do ensino fundamental: uma análise dos conteúdos. REVISTA REAMEC, Cuiabá, v. 6, p. 107-123, 2018. DOI:

https://doi.org/10.26571/REAMEC.a2018.v6.n1.p107-123.i6073.

PEREIRA, E. M. A História da Matemática nos livros didáticos de Matemática do Ensino Médio: conteúdos e abordagens. 2016. 107 f. Orientadora: Mariana FeiteiroCavalari.

Dissertação (Mestrado Profissional em Ensino de Ciências) - Universidade Federal de Itajubá, Minas Gerais, 2016. Disponível em:

https://repositorio.unifei.edu.br/xmlui/bitstream/handle/123456789/476/dissertacao pereira 2016.p df. Acesso em: 03 set. 2020. 
REAME, E. Ligamundo: Matemática Ensino Fundamental anos iniciais. 1. ed. São Paulo: Saraiva, 2017.

SÁ-SILVA, J. R.; ALMEIDA, C. D.; GUINDANI, J. F. Pesquisa documental: pistas teóricas e metodológicas. Revista Brasileira de História \& Ciências Sociais, Rio Grande, v. 1, p. 1-15, 2009. Disponível em: https://periodicos.furg.br/rbhcs/article/view/10351/0. Acesso em: 01 set. 2020.

SANTOS, L. M. Metodologia do ensino de Matemática e Física: Tópicos de história da física e da matemática. 1. ed. Curitiba: Ibpex, 2009.

SANTOS, J. C. A. P. Vem Voar: Matemática - anos iniciais do Ensino Fundamental. 1. ed. São Paulo: Scipione, 2017.

SOUZA, F. J. S.; FORTALEZA, F. J. S. A História da Matemática no Ensino dos Anos Iniciais do Ensino Fundamental: Reflexões a partir dos PCN. In: ENCONTRO NACIONAL DE EDUCAÇÃO MATEMÁTICA, XII, 2016, São Paulo. Anais [...]. São Paulo: SBEM, 2016. p. 1-12. Disponível em: http://www.sbem.com.br/enem2016/anais/pdf/8372 4193 ID.pdf. Acesso em: 12 set. 2020. 